\title{
Infection in Women?
}

\section{INTRODUCTION}

Chlamydia trachomatis (CT) is the most commonly diagnosed sexually transmitted infection (STI) in the UK ${ }^{1}$. While men who have sex with men (MSM) are known to be at-risk of rectal chlamydia infection (ReCT), less is known about the prevalence of ReCT in women².

Undiagnosed ReCT in women may have important implications for chlamydia control as azithromycin, a first line regimen for uncomplicated urogenital infections, may be less effective for treatment of ReCT than other regimens. ${ }^{2}$

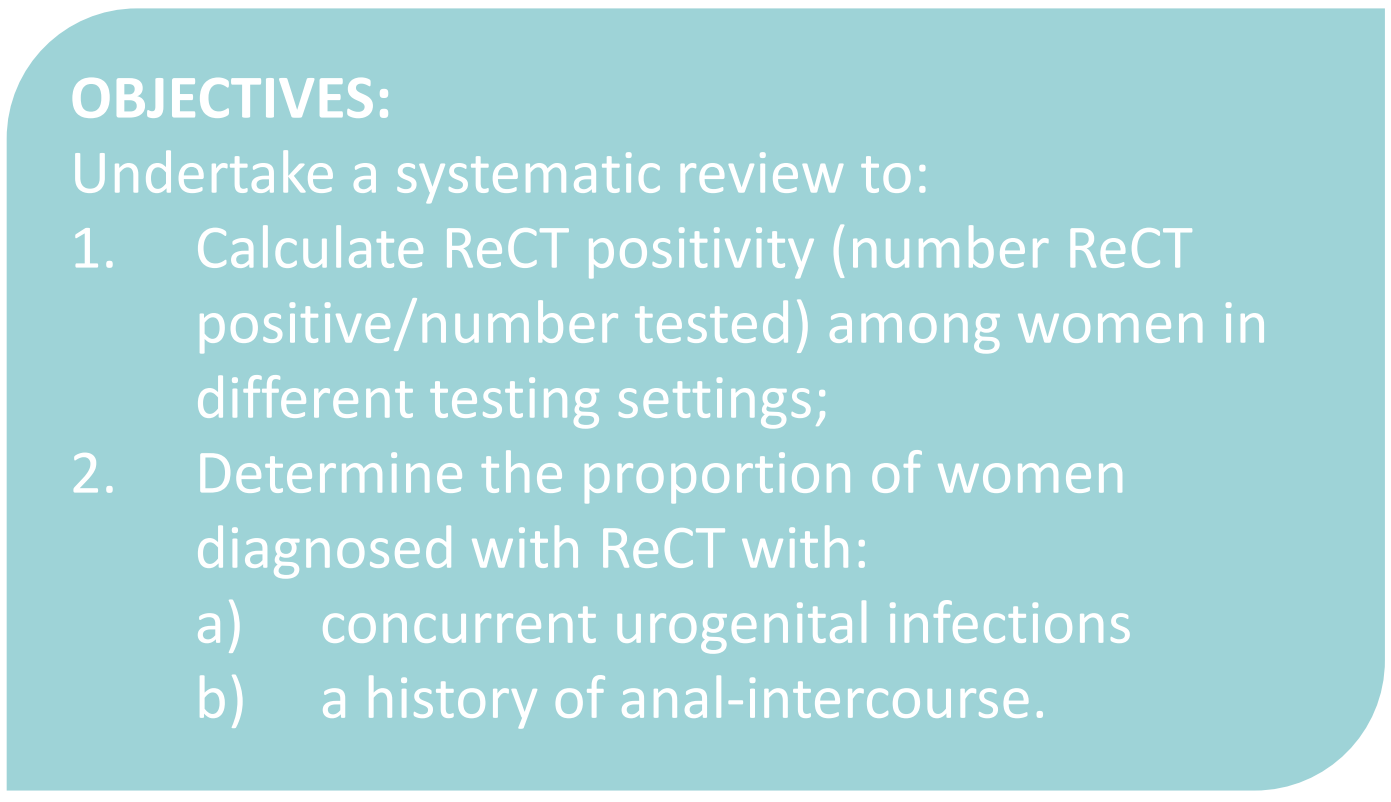

\section{METHODS}

Medline, Embase, CINAHL, PsychINFO and the Cochrane Database were systematically searched for articles published between January 1997 and September 2015.

Studies reporting ReCT positivity in women aged $\geq 15$ years in high-income countries were included and relevant data extracted (e.g. urogenital infection; rectal infection; history of anal-intercourse; demographic data).

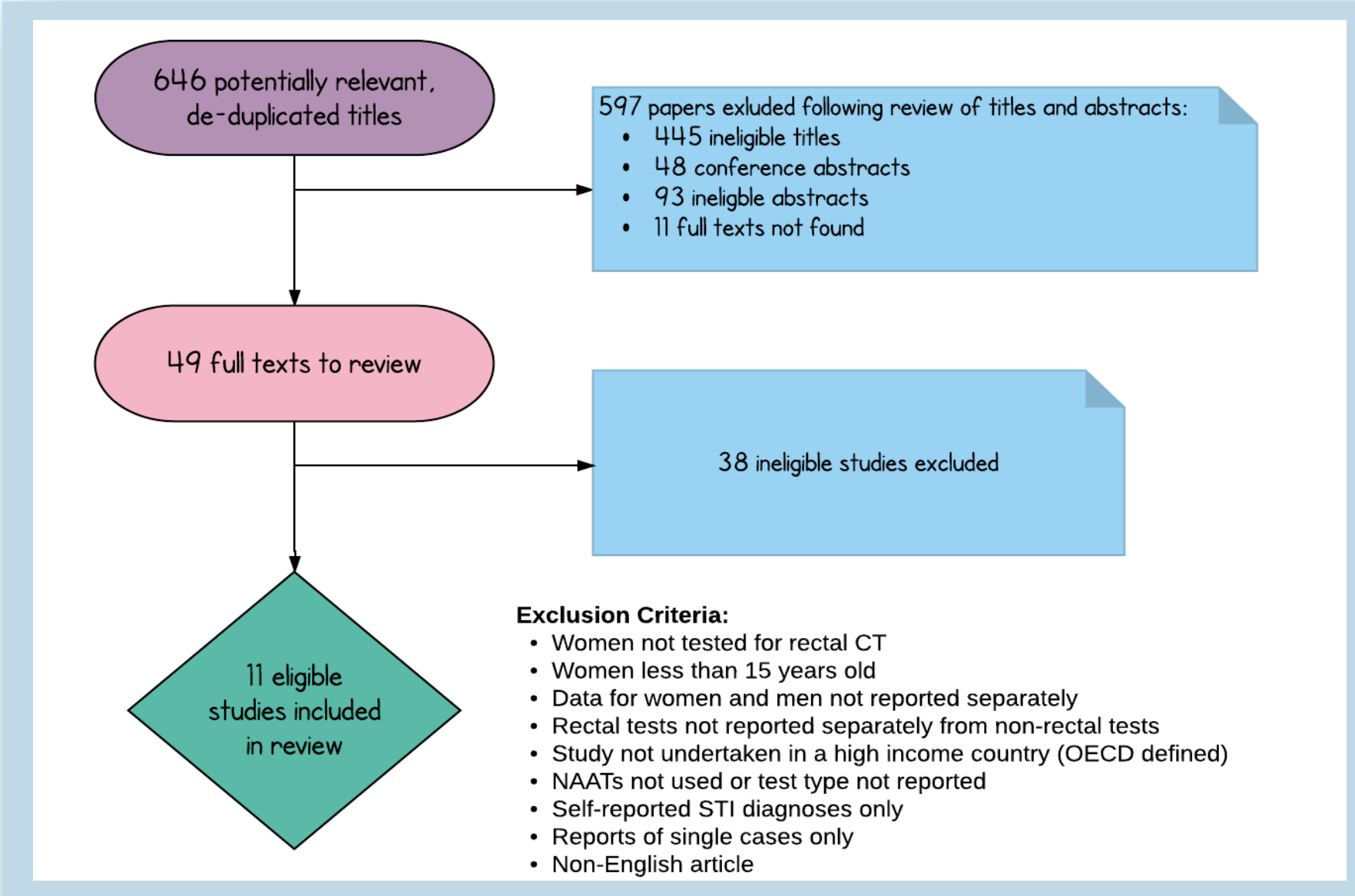

Figure 1: Flow chart depicting the selection of studies for inclusion in the review process.

\section{RESULTS}

- Eleven studies were included, all of which investigated women attending sexual health services.

- Populations tested varied:

- $\quad 3 / 11$ studies recruited only women who reported a history of anal-intercourse;

- $1 / 11$ was conducted only among HIV positive patients;

- $2 / 11$ were conducted only among urogenital CT positive participants;

- $1 / 11$ was conducted among adult film industry performers;

- 4/11 included all eligible clinic-attendees.

- Among all studies, ReCT positivity ranged from $2-77 \%$ (median $8 \%$; see table 1 ).

- Among women with $\mathrm{ReCT}, 41-100 \%$ had a concurrent CT urogenital infection; $13-100 \%$ reported a history of analintercourse (where data were available; see table 1).

\begin{tabular}{|c|c|c|c|c|}
\hline & \multirow{2}{*}{$\begin{array}{l}\text { Number of } \\
\text { studies } \\
\text { where data } \\
\text { reported }\end{array}$} & \multirow[t]{2}{*}{ Median (\%) } & \multicolumn{2}{|c|}{ Range (\%) } \\
\hline & & & Minimum & Maximum \\
\hline $\begin{array}{l}\text { Percentage testing positive } \\
\text { for rectal chlamydia } \\
\text { (positivity) }\end{array}$ & 11 & 8 & 2 & 77 \\
\hline $\begin{array}{l}\text { Site of infection among } \\
\text { women testing positive for } \\
\text { chlamydia: }\end{array}$ & 9 & & & \\
\hline Rectal only & & 6 & 0 & 31 \\
\hline Rectal and urogenital & & 78 & 41 & 100 \\
\hline Urogenital only & & 13 & 0 & 50 \\
\hline $\begin{array}{l}\text { Percentage reporting } \\
\text { history of anal-intercourse } \\
\text { among women testing } \\
\text { positive for rectal } \\
\text { chlamydia* }\end{array}$ & 9 & 36 & 13 & 100 \\
\hline
\end{tabular}

Table 1: Key findings from studies ( $n=11$ ) reporting rectal chlamydia test positivity among women.

*Includes studies ( $n=3$ ) where a history of anal-intercourse was a pre-requisite for study inclusion, excluding these studies the range would be $13-50 \%$ with a median of $28 \%$.

\section{DISCUSSION}

ReCT infections have been found in a substantial proportion of women in the populations included in this analysis. In these studies, urogenital testing alone would have missed up to $31 \%$ of chlamydia infections and may have put some women at risk of inadequate treatment for concurrent ReCT infections, particularly if the preferred treatment regimen for ReCT of doxycycline ${ }^{2}$ was not used for treatment.

The populations included in this review were women attending sexual health services; this population may have a higher risk of STIs compared to the general population. Therefore, due to the paucity of evidence, both ReCT prevalence among women attending sexual health clinics and in the general population remains unclear. Further work to establish need, criteria and feasibility for routine ReCT testing in women is needed to ensure chlamydia infections are not missed or inadequately treated. 